\title{
Dissociating Empathy From Perspective-Taking: Evidence From Intra- and Inter-Individual Differences Research
}

\author{
Julia Stietz ${ }^{1}$, Emanuel Jauk ${ }^{1}$, Sören Krach ${ }^{2}$ and Philipp Kanske ${ }^{1,3 *}$ \\ ${ }^{1}$ Faculty of Psychology, Clinical Psychology and Behavioral Neuroscience, Technische Universität Dresden, Dresden, \\ Germany, ${ }^{2}$ Social Neuroscience Lab, Department of Psychiatry and Psychotherapy, University of Lübeck, Lübeck, Germany, \\ ${ }^{3}$ Research Group Social Stress and Family Health, Max Planck Institute for Human Cognitive and Brain Sciences, \\ Leipzig, Germany
}

OPEN ACCESS

Edited by:

Simon Surguladze,

King's College London,

United Kingdom

Reviewed by:

Sina Radke,

RWTH Aachen Universität, Germany

Gadi Gilam,

Stanford University, United States

*Correspondence:

Philipp Kanske

philipp.kanske@tu-dresden.de

Specialty section:

This article was submitted to

Social Cognition,

a section of the journal

Frontiers in Psychiatry

Received: 18 November 2018

Accepted: 20 February 2019

Published: 14 March 2019

Citation:

Stietz J, Jauk E, Krach S and

Kanske P (2019) Dissociating

Empathy From Perspective-Taking:

Evidence From Intra- and

Inter-Individual Differences Research.

Front. Psychiatry 10:126.

doi: 10.3389/fpsyt.2019.00126
Humans have the capacity to share others' emotions, be they positive or negative. Elicited by the observed or imagined emotion of another person, an observer develops a similar emotional state herself. This capacity, empathy, is one of the pillars of social understanding and interaction as it creates a representation of another's inner, mental state. Empathy needs to be dissociated from other social emotions and, crucially, also from cognitive mechanisms of understanding others, the ability to take others' perspective. Here, we describe the conceptual distinctions of these constructs and review behavioral and neural evidence that dissociates them. The main focus of the present review lies on the intraindividual changes in empathy and perspective-taking across the lifespan and on interindividual differences on subclinical and clinical levels. The data show that empathy and perspective-taking recruit distinct neural circuits and can be discerned already during early and throughout adult development. Both capacities also vary substantially between situations and people. Differences can be systematically related to situational characteristics as well as personality traits and mental disorders. The clear distinction of affect sharing from other social emotions like compassion and from cognitive perspective-taking, argues for a clear-cut terminology to describe these constructs. In our view, this speaks against using empathy as an umbrella term encompassing all affective and cognitive routes to understanding others. Unifying the way we speak about these phenomena will help to further research on their underlying mechanisms, psychopathological alterations, and plasticity in training and therapy.

Keywords: empathy, perspective-taking, theory of mind, lifespan development, personality, mental disorders

\section{EMPATHY AND PERSPECTIVE-TAKING}

When confronted with someone else's emotions, people often spontaneously share that affective state-your grief can become my grief, your joy, my joy. Such a vicarious, isomorphic emotion in an observer of another person's emotions has been referred to as empathy, a term introduced by Vischer and Lipps as "Einfühlung" (German for "feeling into," derived from the Greek empatheia) (1). In humans, empathy may even arise, when the other is not present, but thought of or imagined. Critically, however, it has been proposed to involve self-other distinction, that is, the awareness that another is the source of one's emotions, differentiating it from emotional contagion, where such an awareness is not present (2). 
Of course, empathic affect sharing is only one possible response to another person's emotion. Complementary affective states such as schadenfreude, envy or compassion occur as well, but the peculiarity of empathy is that it enables access to another's internal state by re-creating a representation of that state in the observer (3-6). Correspondingly, neuroscience research on empathy has not identified one single neural network associated with empathy, but rather the brain regions found to be active depend on what affective state is shared. While empathy for others' pain and negative affect activate the anterior insula and anterior midcingulate cortex (core nodes of the salience network), sharing others' joy and positive emotion yields activity in the ventral striatum and medial orbitofrontal cortex (Figure 1) (8-10). These activations seem to be relatively high-level, affective representations, as the specific patterns associated with one negative state, for instance, empathic pain, enable predictions of other negative states such as empathic disgust or unfairness (11). Furthermore, first-hand and empathic emotion experience-being stimulated painfully or watching someone else in pain-also lead to mutually predictive activation patterns in anterior insula and anterior cingulate cortex $(12,13)$. The observation of such "shared neural networks" has been interpreted as agreeing with simulation theory's account of how we understand others-we impersonate them and imitate their mental states (14).

Empathy, then, needs to be differentiated from an alternative route to understanding others. Theory theory, assumes abstract, propositional knowledge about others' behavior to underlie the understanding of the motives that drive others' behavior (15). This conceptualization corresponds to psychological and neuroscience research on perspective-taking or Theory of Mind (ToM), the capacity to make inferences about and represent others' intentions, goals and motives (other terms include mentalizing and cognitive empathy) $(16,17)$. A classic test of ToM is false-belief understanding. If I can apprehend your incorrect view on a matter, while knowing the actual truth, the information conflicts and I must represent it in an abstract manner (18). Neuroscientific investigations of false-belief understanding have identified a network of brain regions to be involved, including the temporoparietal junction, precuneus/posterior cingulate cortex, medial prefrontal regions as well as the temporal poles and superior temporal sulcus (partially overlapping with the default mode network; Figure 1) $(19,20)$. While the main nodes of this network are also involved in other experimental paradigms assessing ToM, some regions within the overall network seem to be specific for particular ToM tasks $(21,22)$. Assuming a "constructivist view" on ToM (23), this may be due to different tasks drawing different component processes of ToM (24). Ecologically complex ToM tasks, in contrast, activate the entire network, possibly because all component processes are required $(25,26)$.

Thus, the abilities to empathically share others' affect and take their perspective can be well-differentiated conceptually and have more recently also been directly dissociated on a neural network level (for a summary see Table 1) (25). However, they may also interact and facilitate or impair one another in complex situations that require both functions simultaneously. For instance, Lamm et al. (8) meta-analytically contrasted cue-based and picture-based empathy for pain studies. When only presented with abstract cues of how painfully another person is stimulated, regions in the ToM-related neural network are activated, possibly reflecting the reasoning about the other's state, which then facilitates or enables empathic sharing of that state. In contrast, when the painful stimulation is directly displayed, ToM is not required to empathize and ToM-related neural activity is absent. Similarly, brain regions in inferior parietal and frontal cortex that have been associated with motor simulation ["mirror neuron system; "(27)] can also trigger empathic responding, if an action needs to be understood for the affective consequences to become clear (28). Empathy and ToM can also show a different interactive pattern in highly emotional situations. Here, ToM performance has been found to be impaired, which is associated with an inhibitory influence of empathy-related anterior insula activation on ToM-related temporoparietal junction activation (29). This may reflect an adaptive response to highly salient situations requiring immediate action, but could also turn maladaptive as has been hypothesized with a stress-related mentalizing deficit in borderline personality disorder (30).

Given the distinguishable neural networks enabling empathy and ToM, it is interesting to ask, if they share interdependent or distinct developmental trajectories over the lifespan, which we will discuss in the next section.

\section{INTRAINDIVIDUAL DIFFERENCES}

\section{Lifespan Development}

Speaking with the words of Hutman and Dapretto (31): "Determining the age at which infants display empathy depends in large part upon the way the construct is defined." Defining empathy as above-as sharing others' emotions while being able to differentiate between oneself and the other-it could be argued that empathy emerges very early in life. Precursors of affect sharing, like emotional contagion, and indirect selfother distinction can already be observed in newborns, well before the emergence of verbal abilities (31-33). For instance, infants display greater and longer distress when confronted with the cry of another newborn compared to their own (34). During childhood, these capacities refine and become more explicit-they can be named and regulated (35-37). Thus, there is no clear age cut-off at which empathy is fully developed or not. Determining the age at which infants display empathy depends on the methods used to capture it-observational and physiological measures, adult-reports or self-reports-which vary highly in their validity and outcomes throughout development (38). With incremental development of its subcomponents and language abilities empathy becomes more apparent and easier to quantify in preschool children. It further develops during adolescence with increases from age 12 to 16 years (39). In sum, the emergence and development of empathy depends strongly on the definitions and methods used, but first signs of affect sharing are already present in newborns.

For ToM, numerous studies show that classical tests of falsebelief understanding are not passed before the age of 4-5 years (40). However, when tested with non-traditional tasks, early preverbal ToM abilities such as mental state attribution and 


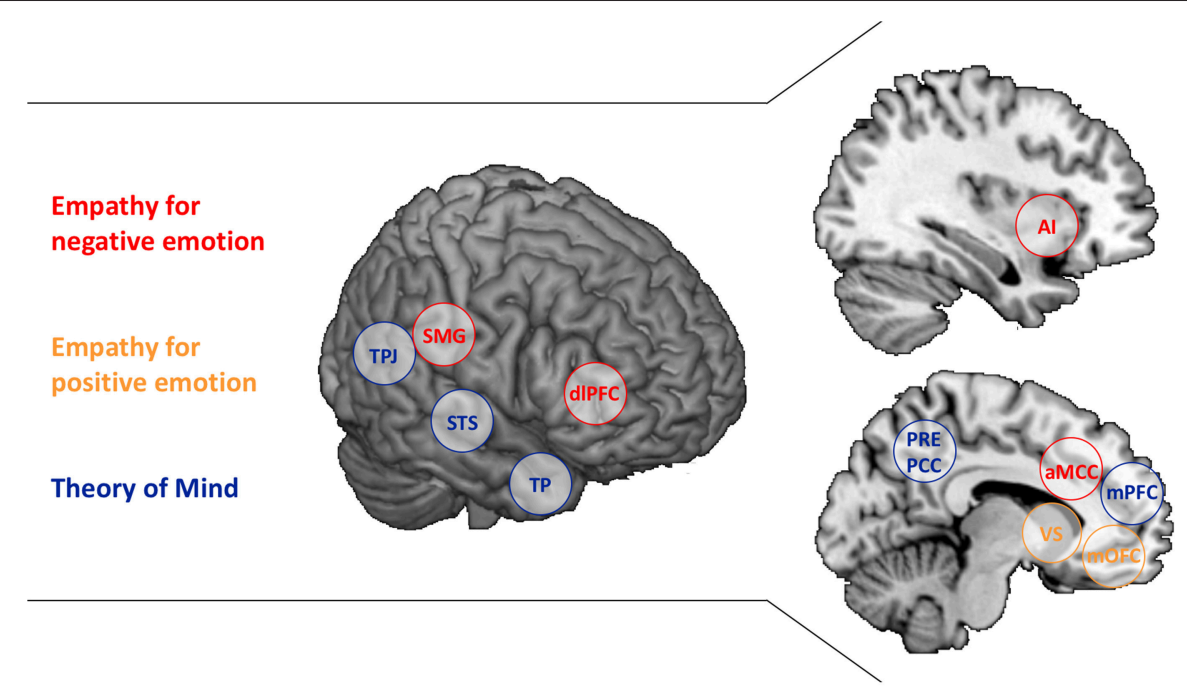

FIGURE 1 | Brain regions associated with Empathy and Theory of Mind. The separable brain regions associated with Empathy for negative emotion (red), Empathy for positive emotion (yellow), and Theory of Mind (blue) are presented. Al, anterior insula; aMCC, anterior middle cingulate cortex; dIPFC, dorsolateral prefrontal cortex; mOFC, medial orbitofrontal cortex; mPFC, medial prefrontal cortex; PCC, posterior cingulate cortex; PCUN, Precuneus; SMG, supramarginal gyrus; STS, superior temporal sulcus; TP, temporal poles; TPJ, temporoparietal junction; VS, ventral striatum. SMG and dIPFC are listed as well as they have been associated with regulating empathic emotion (7).

TABLE 1 | Summary of the conceptual and empirical dissociation of empathy and perspective-taking.

\begin{tabular}{ll}
\hline Empathy & Perspective-taking \\
\hline - Affective process & - Cognitive process \\
- Sharing another's emotional state & - Taking another's perspective \\
- Awareness that other is source & - Abstract representation of others' \\
of emotion & mental state \\
- Involved brain regions depend on & - Widespread network for \\
emotional valence, largely overlaps with & information processing, core nodes \\
salience network & overlap with default mode network \\
- Develops ontogenetically early, does not & - Later ontogenetic development, \\
decline in old age & declines in old age \\
- State/trait reductions mainly for & - State/trait reductions for \\
motivational/habitual reasons & motivational/habitual and \\
& cognitive reasons \\
\hline
\end{tabular}

intentional communication seem to emerge already in infancy at 6-9 months of age, gradually developing further throughout the first years of life $(18,41-44)$. Setoh et al. (45) could further demonstrate that 2.5-year-olds are able to succeed in classic false belief tasks if overall processing demands are reduced by lowering inhibitory control and response-generation demands. This supports the view that ToM also develops incrementally, starting before the age of 4-5 years.

Taken together, empathy and ToM become well-measurable in preschool aged children with increasing abilities in language and executive function. Nevertheless, non-verbal precursors of both capacities are already observable in infancy, in newborns for empathy and from about 6 months on for ToM. Longitudinal studies testing both empathy and ToM jointly, which could yield the most profound evidence for independent trajectories throughout childhood, are still missing. Recently, a crosssectional study examined empathy and ToM within a single group of children ranging from 3 to 5 years of age (46). Children had to pass a certain number of subtasks for empathy and ToM to be classified as having developed either ability. ToM seemed to emerge at 4 years and empathy at 5 years of age. Interestingly, a subgroup of kids, including 4-and 5-year olds, displayed empathy but not ToM. These results cannot yet answer if the development of empathy follows ToM or vice versa, but they hint at some independence in their developmental trajectories.

While numerous studies addressed the emergence of empathy and ToM in childhood, growing evidence also sheds light on their development in old age. In a recent cross-sectional study (47) younger and older adults performed a newly developed naturalistic task which measures both empathy and ToM within the same individuals [EmpaToM; (25)]. Older adults performed significantly worse than younger participants on the ToM questions whereas empathy was still preserved in older adults. These findings are in line with previous studies in younger and older adults, separately testing their abilities to empathize (48-50) and to take others' perspectives (51). The decline of ToM in older adults is a consistent finding across various ToM tasks regardless of stimulus modality or the specific form of ToM that is measured (52). For empathy, in contrast, no age-related changes or even increases with age have been reported (53-55). These findings depict independent developmental paths for empathy and ToM in old age.

Taken together, empathy and ToM evolve and decline independently during lifespan development. A number of factors have been found to influence this development, particularly in childhood, including preterm birth (56), child to parent 
attachment (37), language use of the parents $(57,58)$, mental disorders of the parents (59), the presence of older siblings $(60,61)$ and the specific culture a child grows up in $(62,63)$. Such influencing factors cause interindividual differences in empathy and ToM that could even reach into psychopathology and might be greatly informative regarding the relation of the capacities-a question we discuss in the following section.

\section{State Variability}

While typically developed adults possess the capacity to empathize and take others' perspectives, there is still variation in the propensity to translate this capacity into actual behavior. Whether and to what extent we empathize with others or take their perspectives may depend on situational and relational variables as well as motivational factors (2). Empathic processes are generally more salient in situations in which we are confronted with negative rather than positive emotions [e.g., (64)]. We display stronger empathic reactions when interacting with those we are closely affiliated with (65), which points to a central role of empathy in human and non-human evolution $(66,67)$. This is supported by recent advances in understanding the role of oxytocin in both, empathy and attachment (68). Similarly, we tend to experience higher empathy toward ingroup others, and lower empathy toward outgroup others (69), even when group membership is experimentally varied (70). We typically experience low empathy in states of personal distress or depression (71), particularly due to an incapacity to inhibit own emotional states (72).

ToM is high in states in which we are motivated to understand others' mental states and intentions, which allows making predictions about their actions, and also to influence these actions (16). This can happen for altruistic or also egoistic motives. For instance, one might take another's perspective to be better able to help them, or also to effectively manipulate them. ToM can be low in states which may block the cognitive route to understanding others, such as alcohol intoxication (73), or also depression (74). Though reduced ToM in depression is frequently hypothesized to emerge from heightened egocentric focus, it is not fully understood whether alterations of ToM in depression, for example, are specific to social cognition, or might also be attributed to deficits in executive functioning (75). This highlights the necessity of controlling for general processing capacity in studies investigating individual differences in ToM.

Taken together, contextual factors substantially determine the extent to which we engage in empathy and ToM. Contextual factors may also guide whether we engage affective or cognitive routes to understanding others, which reflects in the respective neural activation (76).

\section{INTERINDIVIDUAL DIFFERENCES}

Beyond transient variations in empathy and ToM, there are also interindividual difference variables that are reliably associated with dispositional variation.

At a most basic level, women score higher on selfreport measures of empathy than men, which may be due to gender-role stereotypes (77) as gender differences are not clearly present in neural empathy responses [but seem to depend largely on context effects, (78)]. Among the Big Five personality traits, agreeableness is most consistently and strongly linked to variation in empathy [e.g., (79)], which has recently been substantiated by neuroimaging research (80). Agreeable individuals have a higher propensity to display empathic reactions, or conversely, empathy can be thought of as a low-level function that serves higher-order facets of agreeableness, such as altruism. Regarding lowered empathic responses, the "dark" personality traits narcissism, Machiavellianism and psychopathy (81) are commonly associated with reduced empathy [e.g., (82)]. These are tied together by interpersonal antagonism-the opposite of agreeableness-in terms of a self-focused and callous interpersonal style (83). Emotional contagion and empathy are typically lower in narcissism $(82,84,85)$ and psychopathy $(86,87)$. Interestingly, empathic alterations in narcissism and psychopathy are not due to an incapacity to empathize, but rather due to motivational factors. Experimental evidence shows that narcissistic individuals experience regular levels of empathy when being instructed to put themselves into the perspective of a suffering person (88). Similarly, psychopathic individualsviewed as similar, yet more severely disordered (89)—can indeed experience empathy. Psychopathic individuals show similar brain activation as controls in the anterior insula and anterior cingulate cortex, but only deliberately, not spontaneously (90). This confirms the notion of reduced propensity for empathic reactions, not reduced capacity in terms of general inability to share others' affect, in psychopathic individuals.

While the majority of individual differences research on empathy focuses on variables that are accompanied by lowered empathy, there are also examples in which empathy is hypothesized to be higher. For instance, clinical observations suggest the existence of "borderline empathy" in terms of surprisingly accurate emotional resonance in individuals with borderline personality disorder (91). The overall evidence on borderline empathy, however, is mixed (92), and some research indicates that the phenomenon might be conceptualized in terms of increased emotion recognition ability [e.g., (93)], which does not necessarily involve affective sharing.

Unlike empathy, variation in ToM is less clearly associated with sex [e.g., (94)], but similarly associated with the Big Five dimension of agreeableness; particularly when complex ToM measures are used (95). ToM is also not uniformly lowered in the Dark Triad traits [e.g., (96)]. A recent study found that only automatic ToM is lowered in psychopathy, whereas controlled ToM does not differ from controls (97). This points to a diminished propensity rather than capacity to take others' perspective, which highlights the motivational role of personality characteristics in ToM. Taking this idea one step further, there is even evidence for increased social cognition in individuals high on "dark" personality traits, which could enable antagonistic individuals to effectively deceive and manipulate others $(98,99)$.

Taken together, research on intra- and interindividual differences shows that there is substantial variation in affective and cognitive interpersonal functioning. Both can be selectively heightened or lowered, depending on state and trait characteristics. This corresponds to behavioral and neuroscience evidence showing that strong empathizers are not necessarily better mentalizers, and vice versa (29). Whether 
and to what extent we empathize and take others' perspectives depends substantially on situational and motivational variables, the latter of which reflect in personality traits. Altered social affect and cognition related to personality traits and disorders are likely more a matter of reduced propensity than capacity.

\section{CONCLUSION AND OUTLOOK}

While the phenomena of affect sharing and perspective-taking may be relatively well-understood, there is considerable variation in the terminology used to describe them. The definition of empathy ranges from confining it to affect sharing [applied in the current review; (2)] to a very broad usage as an umbrella term. The latter view would merge (i) affect sharing, personal distress and emotional empathy as an emotional and (ii) mentalizing, perspective-taking and ToM as a cognitive component of empathy $(100,101)$. Here, we reviewed evidence that dissociates these functions, with differential neural networks related to empathy and ToM (Figure 1). Lifespan developmental research further indicates independent trajectories - the affective route seems to develop earlier and remains unaffected by aging compared to the cognitive route. Moreover, state variables like the shared emotions' valence, the experienced affiliation with others or the motivation to take someone's perspective and personality traits like agreeableness selectively affect the intraand interindividual capacity to empathize or to engage in ToM (see Table 1 for a summary).

Given this separability of the phenomena of affect sharing and perspective-taking, we argue for clear-cut terminology that differentiates among them. An argument for restraining the term empathy to affect sharing, as is being done in a large portion of the current literature $(2,3,46,47,102,103)$, is that it makes usage of the term unmistakable and distinctive. The umbrella usage, in contrast, requires specification as to which component is actually referred to in order to avoid misunderstanding. While

\section{REFERENCES}

1. Titchener EB. Introspection and empathy. Dialogues Philos Ment Neuro Sci. (2014) 7:25-30.

2. de Vignemont F, Singer T. The empathic brain: how, when and why? Trends Cogn Sci. (2006) 10:435-41. doi: 10.1016/j.tics.2006.08.008

3. Kanske P. The social mind: disentangling affective and cognitive routes to understanding others. Interdiscip Sci Rev. (2018) 43:115-24. doi: 10.1080/03080188.2018.1453243

4. Paulus FM, Müller-Pinzler L, Westermann S, Krach S. On the distinction of empathic and vicarious emotions. Front Hum Neurosci. (2013) 7:196. doi: 10.3389/fnhum.2013.00196

5. Kanske P, Böckler A, Singer T. Models, mechanisms and moderators dissociating empathy and theory of mind. In: M. Wöhr, S. Krach, editors. Social Behavior From Rodents to Humans: Neural Foundations and Clinical Implications Current Topics in Behavioral Neurosciences. Cham: Springer International Publishing. (2017).p. 193-206. doi: 10.1007/7854_2015_412

6. Paulus FM, Müller-Pinzler L, Stolz DS, Mayer AV, Rademacher L, Krach S. Laugh or cringe? Common and distinct processes of reward-based schadenfreude and empathy-based fremdscham. Neuropsychologia. (2018) 116:52-60. doi: 10.1016/j.neuropsychologia.2017. 05.030

7. Steinbeis N, Bernhardt BC, Singer T. Age-related differences in function and structure of rSMG and reduced functional connectivity with DLPFC a few studies also dissociate affective and cognitive components of ToM (104), the term ToM is used much more consistently already for what the umbrella usage would describe as cognitive empathy. Thus, there is no need for or reason to expand the term empathy to account for the phenomenon of perspective-taking. We believe clear-cut terminology is best suited to further research in the field $(105,106)$.

Foci of future research should be on (i) longitudinal developmental investigations, (ii) comprehensive assessments of empathy and ToM in psychopathology and subclinical variability as well as (iii) probing the differential plasticity of these social affective and cognitive capacities. Longitudinal studies could give in-depth understanding of the bases and influencing factors that affect the emergence and decline in empathy and perspectivetaking. Differential development of the underlying brain structures could be informative regarding the differentiation of developmental empathy and ToM trajectories (107). Further research on situational, personality, and psychopathology factors related to empathy and ToM is needed to understand whether differences reflect alterations in the propensity or the capacity to mobilize these functions. Lastly, first evidence on the differential plasticity of social affect and cognition $(108,109)$ should be followed up with studies in clinical groups that show social interaction deficits.

\section{AUTHOR CONTRIBUTIONS}

All authors listed have made a substantial, direct and intellectual contribution to the work, and approved it for publication.

\section{FUNDING}

Research leading to this publication was funded by the German Federal Ministry of Education and Research (BMBF, grant number: FKZ 01EE1409A). Funding period: 2015-2019. explains heightened emotional egocentricity bias in childhood. Soc Cogn Affect Neurosci. (2015) 10:302-10. doi: 10.1093/scan/nsu057

8. Lamm C, Decety J, Singer T. Meta-analytic evidence for common and distinct neural networks associated with directly experienced pain and empathy for pain. NeuroImage. (2011) 54:2492-502. doi: 10.1016/j.neuroimage.2010.10.014

9. Lamm C, Silani G, Singer T. Distinct neural networks underlying empathy for pleasant and unpleasant touch. Cortex J Devoted Study Nerv Syst Behav. (2015) 70:79-89. doi: 10.1016/j.cortex.2015.01.021

10. Mobbs D, Yu R, Meyer M, Passamonti L, Seymour B, Calder AJ, et al. A key role for similarity in vicarious reward. Science. (2009) 324:900. doi: $10.1126 /$ science.1170539

11. Corradi-Dell'Acqua C, Tusche A, Vuilleumier P, Singer T. Crossmodal representations of first-hand and vicarious pain, disgust and fairness in insular and cingulate cortex. Nat Commun. (2016) 7:10904. doi: $10.1038 /$ ncomms 10904

12. Corradi-Dell'Acqua C, Hofstetter C, Vuilleumier P. Felt and seen pain evoke the same local patterns of cortical activity in insular and cingulate cortex. J Neurosci Off J Soc Neurosci. (2011) 31:17996-8006. doi: 10.1523/JNEUROSCI.2686-11.2011

13. Oosterwijk S, Snoek L, Rotteveel M, Barrett LF, Scholte HS. Shared states: using MVPA to test neural overlap between self-focused emotion imagery and other-focused emotion understanding. Soc Cogn Affect Neurosci. (2017) 12:1025-35. doi: $10.1093 / \mathrm{scan} / \mathrm{nsx} 037$ 
14. Gallese V, Goldman A. Mirror neurons and the simulation theory of mindreading. Trends Cogn Sci. (1998) 2:493-501.

15. Gopnik A, Wellman HM. The theory theory. In: Hirschfeld LA, Gelman SA, editors. Mapping the Mind: Domain Specificity in Cognition and Culture. New York, NY: Cambridge University Press. (1995). p. 257-93. doi: 10.1017/CBO9780511752902.011

16. Frith C, Frith U. Theory of mind. Curr Biol CB. (2005) 15:R644-6. doi: 10.1016/j.cub.2005.08.041

17. Premack D, Woodruff G. Does the chimpanzee have a theory of mind? Behav Brain Sci. (1978) 1:515-26. doi: 10.1017/S0140525X00076512

18. Wimmer H, Perner J. Beliefs about beliefs: representation and constraining function of wrong beliefs in young children's understanding of deception. Cognition. (1983) 13:103-28. doi: 10.1016/0010-0277(83)90004-5

19. Bzdok D, Schilbach L, Vogeley K, Schneider K, Laird AR, Langner R, et al. Parsing the neural correlates of moral cognition: ALE meta-analysis on morality, theory of mind, and empathy. Brain Struct Funct. (2012) 217:78396. doi: 10.1007/s00429-012-0380-y

20. Shamay-Tsoory SG, Aharon-Peretz J, Perry D. Two systems for empathy: a double dissociation between emotional and cognitive empathy in inferior frontal gyrus versus ventromedial prefrontal lesions. Brain. (2009) 132:61727. doi: 10.1093/brain/awn279

21. Schurz M, Radua J, Aichhorn M, Richlan F, Perner J. Fractionating theory of mind: a meta-analysis of functional brain imaging studies. Neurosci Biobehav Rev. (2014) 42:9-34. doi: 10.1016/j.neubiorev.2014.01.009

22. Molenberghs $\mathrm{P}$, Johnson H, Henry JD, Mattingley JB. Understanding the minds of others: a neuroimaging meta-analysis. Neurosci Biobehav Rev. (2016) 65:276-91. doi: 10.1016/j.neubiorev.2016.03.020

23. Schaafsma SM, Pfaff DW, Spunt RP, Adolphs R. Deconstructing and reconstructing theory of mind. Trends Cogn Sci. (2015) 19:65-72. doi: 10.1016/j.tics.2014.11.007

24. Schurz M, Perner J. An evaluation of neurocognitive models of theory of mind. Front Psychol. (2015) 6:1610. doi: 10.3389/fpsyg.2015.01610

25. Kanske P, Böckler A, Trautwein F-M, Singer T. Dissecting the social brain: introducing the EmpaToM to reveal distinct neural networks and brainbehavior relations for empathy and theory of mind. NeuroImage. (2015) 122:6-19. doi: 10.1016/j.neuroimage.2015.07.082

26. Wolf I, Dziobek I, Heekeren HR. Neural correlates of social cognition in naturalistic settings: a model-free analysis approach. NeuroImage. (2010) 49:894-904. doi: 10.1016/j.neuroimage.2009.08.060

27. Gallese V, Keysers C, Rizzolatti G. A unifying view of the basis of social cognition. Trends Cogn Sci. (2004) 8:396-403. doi: 10.1016/j.tics.2004.07.002

28. Jabbi M, Keysers C. Inferior frontal gyrus activity triggers anterior insula response to emotional facial expressions. Emotion. (2008) 8:775-80. doi: 10.1037/a0014194

29. Kanske P, Böckler A, Trautwein F-M, Parianen Lesemann FH, Singer T. Are strong empathizers better mentalizers? Evidence for independence and interaction between the routes of social cognition. Soc Cogn Affect Neurosci. (2016) 11:1383-92. doi: 10.1093/scan/nsw052

30. Fonagy P, Luyten P. A developmental, mentalization-based approach to the understanding and treatment of borderline personality disorder. Dev Psychopathol. (2009) 21:1355-81. doi: 10.1017/S0954579409990198

31. Hutman T, Dapretto M. The emergence of empathy during infancy. Cogn Creier Comport Cogn Brain Behav. (2009) 13:367-90.

32. Decety J. The neural pathways, development and functions of empathy. Curr Opin Behav Sci. (2015) 3:1-6. doi: 10.1016/j.cobeha.2014.12.001

33. Tousignant B, Eugene F, Jackson PL. A developmental perspective on the neural bases of human empathy. Infant Behav Dev. (2017) 48:5-12. doi: 10.1016/j.infbeh.2015.11.006

34. Dondi M, Simion F, Caltran G. Can newborns discriminate between their own cry and the cry of another newborn infant? Dev Psychol. (1999) 35:418-26.

35. Knafo A, Zahn-Waxler C, Van Hulle C, Robinson JL, Rhee SH. The developmental origins of a disposition toward empathy: genetic and environmental contributions. Emotion. (2008) 8:737-52. doi: 10.1037/a0014179

36. Roth-Hanania R, Davidov M, Zahn-Waxler C. Empathy development from 8 to 16 months: early signs of concern for others. Infant Behav Dev. (2011) 34:447-58. doi: 10.1016/j.infbeh.2011.04.007
37. Stern JA, Cassidy J. Empathy from infancy to adolescence: an attachment perspective on the development of individual differences. Dev Rev. (2018) 47:1-22. doi: 10.1016/j.dr.2017.09.002

38. Uzefovsky F, Knafo-Noam A. Empathy development throughout the life span. In: Sommerville J, Decety J, editors. Social Cognition: Development Across the Life Span. New York, NY: Routledge/Taylor \& Francis Group. (2017). p. 71-97.

39. Allemand M, Steiger AE, Fend HA. Empathy development in adolescence predicts social competencies in adulthood. J Pers. (2015) 83:229-41. doi: $10.1111 /$ jopy. 12098

40. Wellman HM, Cross D, Watson J. Meta-analysis of theory-of-mind development: the truth about false belief. Child Dev. (2001) 72:655-84. doi: 10.1111/1467-8624.00304

41. Cadinu MR, Kiesner J. Children's development of a theory of mind. Eur J Psychol Educ. (2000) 15:93-111. doi: 10.1007/BF03173169

42. Derksen DG, Hunsche MC, Giroux ME, Connolly DA, Bernstein DM. A systematic review of theory of mind's precursors and functions. $Z$ Für Psychol. (2018) 226:87-97. doi: 10.1027/2151-2604/a000325

43. Kovács ÁM, Téglás E, Endress AD. The social sense: susceptibility to others' beliefs in human infants and adults. Science. (2010) 330:1830-4. doi: 10.1126/science.1190792

44. Slaughter V. Theory of mind in infants and young children: a review. Aust Psychol. (2015) 50:169-72. doi: 10.1111/ap.12080

45. Setoh P, Scott RM, Baillargeon R. Two-and-a-half-year-olds succeed at a traditional false-belief task with reduced processing demands. Proc Natl Acad Sci USA. (2016) 113:13360-5. doi: 10.1073/pnas.16092 03113

46. Brown MM, Thibodeau RB, Pierucci JM, Gilpin AT. Supporting the development of empathy: the role of theory of mind and fantasy orientation. Soc Dev. (2017) 26:951-64. doi: 10.1111/sode.12232

47. Reiter AMF, Kanske P, Eppinger B, Li S-C. The Aging of the social mind differential effects on components of social understanding. Sci Rep. (2017) 7:11046. doi: 10.1038/s41598-017-10669-4

48. Bailey PE, Henry JD, Von Hippel W. Empathy and social functioning in late adulthood. Aging Ment Health. (2008) 12:499-503. doi: 10.1080/13607860802224243

49. Hühnel I, Fölster M, Werheid K, Hess U. Empathic reactions of younger and older adults: no age related decline in affective responding. J Exp Soc Psychol. (2014) 50:136-43. doi: 10.1016/j.jesp.2013.09.011

50. Richter D, Kunzmann U. Age differences in three facets of empathy: performance-based evidence. Psychol Aging. (2011) 26:60-70. doi: $10.1037 / \mathrm{a} 0021138$

51. El Haj M, Raffard S, Gély-Nargeot M-C. Destination memory and cognitive theory of mind in normal ageing. Memory. (2016) 24:526-34. doi: 10.1080/09658211.2015.1021257

52. Henry JD, Phillips LH, Ruffman T, Bailey PE. A meta-analytic review of age differences in theory of mind. Psychol Aging. (2013) 28:826-39. doi: $10.1037 / \mathrm{a} 0030677$

53. Khanjani Z, Jeddi EM, Hekmati I, Khalilzade S, Nia ME, Andalib $\mathrm{M}$, et al. Comparison of cognitive empathy, emotional empathy, and social functioning in different age groups. Aust Psychol. (2015) 50:80-5. doi: 10.1111/ap.12099

54. Sze JA, Gyurak A, Goodkind MS, Levenson RW. Greater emotional empathy and prosocial behavior in late life. Emotion. (2012) 12:1129-40. doi: $10.1037 / \mathrm{a} 0025011$

55. Ze O, Thoma P, Suchan B. Cognitive and affective empathy in younger and older individuals. Aging Ment Health. (2014) 18:929-35. doi: 10.1080/13607863.2014.899973

56. Mossad SI, Smith ML, Pang EW, Taylor MJ. Neural correlates of "Theory of Mind" in very preterm born children. Hum Brain Mapp. (2017) 38:5577-89. doi: 10.1002/hbm. 23750

57. Pamela W. Garner. Child and family correlates of toddlers' emotional and behavioral responses to a mishap. Infant Ment Health J. (2003) 24:580-96. doi: 10.1002/imhj.10076

58. Ebert S, Peterson C, Slaughter V, Weinert S. Links among parents' mental state language, family socioeconomic status, and preschoolers' theory of mind development. Cogn Dev. (2017) 44:32-48. doi: 10.1016/j.cogdev.2017.08.005 
59. Pratt M, Goldstein A, Levy J, Feldman R. Maternal depression across the first years of life impacts the neural basis of empathy in preadolescence. J Am Acad Child Adolesc Psychiatry. (2017) 56:20-9. doi: 10.1016/j.jaac.2016.10.012

60. Tucker CJ, Updegraff KA, McHale SM, Crouter AC. Older siblings as socializers of younger siblings' empathy. J Early Adolesc. (1999) 19:176-98. doi: 10.1177/0272431699019002003

61. Ruffman T, Perner J, Naito M, Parkin L, Clements WA. Older (but not younger) siblings facilitate false belief understanding. Dev Psychol. (1998) 34:161-74. doi: 10.1037/0012-1649.34.1.161

62. Liu D, Wellman HM, Tardif T, Sabbagh MA. Theory of mind development in Chinese children: a meta-analysis of false-belief understanding across cultures and languages. Dev Psychol. (2008) 44:523-31. doi: 10.1037/0012-1649.44.2.523

63. Shahaeian A, Nielsen M, Peterson CC, Slaughter V. Cultural and family influences on children's theory of mind development: a comparison of australian and Iranian school-age children. J Cross-Cult Psychol. (2014) 45:555-68. doi: 10.1177/0022022113513921

64. Morelli SA, Lieberman MD, Zaki J. The emerging study of positive empathy: positive empathy. Soc Personal Psychol Compass. (2015) 9:57-68. doi: $10.1111 /$ spc3.12157

65. Beeney JE, Franklin RG, Levy KN, Adams RB. I feel your pain: emotional closeness modulates neural responses to empathically experienced rejection. Soc Neurosci. (2011) 6:369-76. doi: 10.1080/17470919.2011.557245

66. Decety J. The neuroevolution of empathy. Ann N Y Acad Sci. (2011) 1231:3545. doi: 10.1111/j.1749-6632.2011.06027.x

67. Seyfarth RM, Cheney DL. Affiliation, empathy, and the origins of theory of mind. Proc Natl Acad Sci USA. (2013) 110(Suppl. 2):10349-56. doi: 10.1073/pnas.1301223110

68. Kirsch P. Oxytocin in the socioemotional brain: implications for psychiatric disorders. Dialogues Clin Neurosci. (2015) 17:463-76.

69. Tarrant M, Dazeley S, Cottom T. Social categorization and empathy for outgroup members. Br J Soc Psychol. (2009) 48:427-46. doi: 10.1348/014466608X373589

70. Montalan B, Lelard T, Godefroy O, Mouras H. Behavioral investigation of the influence of social categorization on empathy for pain: a minimal group paradigm study. Front Psychol. (2012) 3:389. doi: 10.3389/fpsyg.2012.00389

71. Kupferberg A, Bicks L, Hasler G. Social functioning in major depressive disorder. Neurosci Biobehav Rev. (2016) 69:313-32. doi: 10.1016/j.neubiorev.2016.07.002

72. Hoffmann F, Banzhaf C, Kanske P, Gärtner M, Bermpohl F, Singer T. Empathy in depression: egocentric and altercentric biases and the role of alexithymia. J Affect Disord. (2016) 199:23-9. doi: 10.1016/j.jad.2016.03.007

73. Mitchell IJ, Beck SR, Boyal A, Edwards VR. Theory of mind deficits following acute alcohol intoxication. Eur Addict Res. (2011) 17:164-8. doi: 10.1159/000324871

74. Bora E, Berk M. Theory of mind in major depressive disorder: a metaanalysis. J Affect Disord. (2016) 191:49-55. doi: 10.1016/j.jad.2015.11.023

75. Berecz H, Tényi T, Herold R. Theory of mind in depressive disorders: a review of the literature. Psychopathology. (2016) 49:125-34. doi: 10.1159/000446707

76. Raz G, Jacob Y, Gonen T, Winetraub Y, Flash T, Soreq E, et al. Cry for her or cry with her: context-dependent dissociation of two modes of cinematic empathy reflected in network cohesion dynamics. Soc Cogn Affect Neurosci. (2014) 9:30-8. doi: 10.1093/scan/nst052

77. Baez S, Flichtentrei D, Prats M, Mastandueno R, García AM, Cetkovich M, et al. Men, women... who cares? A population-based study on sex differences and gender roles in empathy and moral cognition. PLOS ONE. (2017) 12:e0179336. doi: 10.1371/journal.pone.0179336

78. Singer T, Seymour B, O'Doherty JP, Stephan KE, Dolan RJ, Frith CD. Empathic neural responses are modulated by the perceived fairness of others. Nature. (2006) 439:466-9. doi: 10.1038/nature04271

79. Melchers MC, Li M, Haas BW, Reuter M, Bischoff L, Montag C. Similar personality patterns are associated with empathy in four different countries. Front Psychol. (2016) 7:290. doi: 10.3389/fpsyg.2016.00290

80. Haas BW, Brook M, Remillard L, Ishak A, Anderson IW, Filkowski MM. I know how you feel: the warm-altruistic personality profile and the empathic brain. PLoS ONE. (2015) 10:e120639. doi: 10.1371/journal.pone.0120639
81. Paulhus DL, Williams KM. The dark triad of personality: narcissism, machiavellianism, and psychopathy. J Res Personal. (2002) 36:556-63. doi: 10.1016/S0092-6566(02)00505-6

82. Wai M, Tiliopoulos N. The affective and cognitive empathic nature of the dark triad of personality. Personal Individ Differ. (2012) 52:794-9. doi: 10.1016/j.paid.2012.01.008

83. Jones DN, Figueredo AJ. The core of darkness: uncovering the heart of the dark triad. Eur J Personal. (2013) 27:521-31. doi: 10.1002/per.1893

84. Czarna AZ, Wróbel M, Dufner M, Zeigler-Hill V. Narcissism and emotional contagion: do narcissists "catch" the emotions of others? Soc Psychol Personal Sci. (2015) 6:318-24. doi: 10.1177/1948550614559652

85. Giammarco EA, Vernon PA. Vengeance and the dark triad: the role of empathy and perspective taking in trait forgivingness. Personal Individ Differ. (2014) 67:23-9. doi: 10.1016/j.paid.2014.02.010

86. Decety J, Skelly LR, Kiehl KA. Brain response to empathy-eliciting scenarios involving pain in incarcerated individuals with psychopathy. JAMA Psychiatry. (2013) 70:638-45. doi: 10.1001/jamapsychiatry.2013.27

87. Winter K, Spengler S, Bermpohl F, Singer T, Kanske P. Social cognition in aggressive offenders: impaired empathy, but intact theory of mind. Sci Rep. (2017) 7:670. doi: 10.1038/s41598-017-00745-0

88. Hepper EG, Hart CM, Sedikides C. Moving narcissus: can narcissists be empathic? Pers Soc Psychol Bull. (2014) 40:1079-91. doi: 10.1177/0146167214535812

89. Lenzenweger MF, Clarkin JF, Caligor E, Cain NM, Kernberg OF. Malignant narcissism in relation to clinical change in borderline personality disorder: an exploratory study. Psychopathology. (2018) 51:318-25. doi: $10.1159 / 000492228$

90. Meffert H, Gazzola V, den Boer JA, Bartels AAJ, Keysers C. Reduced spontaneous but relatively normal deliberate vicarious representations in psychopathy. Brain J Neurol. (2013) 136:2550-62. doi: 10.1093/brain/awt190

91. Krohn A. Borderline "empathy" and differentiation of object representations: a contribution to the psychology of object relations. Int J Psychoanal Psychother. (1974) 3:142-65.

92. Dinsdale N, Crespi BJ. The borderline empathy paradox: evidence and conceptual models for empathic enhancements in borderline personality disorder. J Personal Disord. (2013) 27:172-95. doi: 10.1521/pedi.2013.27.2.172

93. Fertuck EA, Jekal A, Song I, Wyman B, Morris MC, Wilson ST, et al. Enhanced "Reading the Mind in the Eyes" in borderline personality disorder compared to healthy controls. Psychol Med. (2009) 39:1979-88. doi: 10.1017/S003329170900600X

94. Lucas-Molina B, Pérez-Albéniz A, Ortuño-Sierra J. Dimensional structure and measurement invariance of the interpersonal reactivity index (IRI) across gender. Psicothema. (2017) 29:590-5. doi: 10.7334/psicothema2017.19

95. Nettle D, Liddle B. Agreeableness is related to social-cognitive, but not social-perceptual, theory of mind. Eur J Personal. (2008) 22:323-35. doi: $10.1002 /$ per.672

96. Jonason PK, Krause L. The emotional deficits associated with the dark triad traits: cognitive empathy, affective empathy, and alexithymia. Personal Individ Differ. (2013) 55:532-7. doi: 10.1016/j.paid.2013.04.027

97. Drayton LA, Santos LR, Baskin-Sommers A. Psychopaths fail to automatically take the perspective of others. Proc Natl Acad Sci USA. (2018) 115:3302-7. doi: 10.1073/pnas.1721903115

98. Konrath S, Corneille O, Bushman BJ, Luminet O. The relationship between narcissistic exploitativeness, dispositional empathy, and emotion recognition abilities. J Nonverbal Behav. (2014) 38:129-43. doi: 10.1007/s10919-013-0164-y

99. Nagler UKJ, Reiter KJ, Furtner MR, Rauthmann JF. Is there a "dark intelligence"? Emotional intelligence is used by dark personalities to emotionally manipulate others. Personal Individ Differ. (2014) 65:47-52. doi: $10.1016 /$ j.paid.2014.01.025

100. Feshbach ND. Empathy in children: some theoretical and empirical considerations. Couns Psychol. (1975) 5:25-30. doi: 10.1177/001100007500500207

101. Zaki J. Moving beyond stereotypes of empathy. Trends Cogn Sci. (2017) 21:59-60. doi: 10.1016/j.tics.2016.12.004

102. Singer T, Lamm C. The social neuroscience of empathy. Ann N Y Acad Sci. (2009) 1156:81-96. doi: 10.1111/j.1749-6632.2009.04418.x 
103. Decety J, Jackson PL. The functional architecture of human empathy. Behav Cogn Neurosci Rev. (2004) 3:71-100. doi: 10.1177/1534582304267187

104. Healey ML, Grossman M. Cognitive and affective perspective-taking: evidence for shared and dissociable anatomical substrates. Front Neurol. (2018) 9:491. doi: 10.3389/fneur.2018.00491

105. Cuff BMP, Brown SJ, Taylor L, Howat DJ. Empathy: a review of the concept. Emot Rev. (2016) 8:144-53. doi: 10.1177/1754073914558466

106. Steins G. Diagnosis of empathy and perspective-taking: a review of the relation between these constructs and implications for their measurement. Diagnostica. (1998) 44:117-29.

107. Bottiroli S, Cavallini E, Ceccato I, Vecchi T, Lecce S. Theory of mind in aging: comparing cognitive and affective components in the faux pas test. Arch Gerontol Geriatr. (2016) 62:152-62. doi: 10.1016/j.archger.2015.09.009

108. Valk SL, Bernhardt BC, Trautwein F-M, Böckler A, Kanske P, Guizard N, et al. Structural plasticity of the social brain: differential change after socio-affective and cognitive mental training. Sci Adv. (2017) 3:e1700489. doi: $10.1126 /$ sciadv.17 00489
109. Trautwein F-M, Kanske P, Böckler-Raettig A, Singer T. Differential benefits of mental training types for attention, compassion, and theory of mind. (2017) 8:1488-512. doi: 10.31234/osf.io/k5dqb

Conflict of Interest Statement: SK is Specialty Chief Editor of Frontiers in Psychiatry-Social Cognition.

The remaining authors declare that the research was conducted in the absence of any commercial or financial relationships that could be construed as a potential conflict of interest.

Copyright (0) 2019 Stietz, Jauk, Krach and Kanske. This is an open-access article distributed under the terms of the Creative Commons Attribution License (CC BY). The use, distribution or reproduction in other forums is permitted, provided the original author(s) and the copyright owner(s) are credited and that the original publication in this journal is cited, in accordance with accepted academic practice. No use, distribution or reproduction is permitted which does not comply with these terms. 